\title{
Chapter 4:
}

\section{Case Study: Evolving Purchasing and Collection Models for Serials Author: Hilary Davis, NCSU Libraries}

\section{Introduction:}

Increased demand of e-resources by patrons and the need for management tools to manage these electronic collections by librarians have spurred many libraries to adjust their collections and acquisitions strategies. This chapter will outline the context in which electronic library collections are evolving and the implications of concomitant changes for collections and acquisitions functions. Each case study includes background for which the case libraries decided to embark on a new model for serials collecting and purchasing. Processes and criteria used by each case library are described so that readers can apply some of these methods to work through their own initiatives for building robust electronic collections. Consequent impacts on budgeting, long-term planning, staffing and workflows are also reviewed as lessons learned for the benefit of other libraries considering experimenting with pay-per-view serials access or converting serials collections to electronic-only format. Evaluation tools and benchmarks used by the case libraries provide valuable understanding of the impact of alternative purchasing models and better prepare librarians for undertaking similar efforts.

King and Tenopir (2004) found that approximately 80 percent of use of library resources takes place in electronic format because users find that electronic resources are easier and more convenient to use and save more time.1 To meet users' expectations, libraries that are already functioning within tight resource constraints must develop cost- 
effective collection strategies (Boyce, et al., 2004).2 As a result, more and more libraries are shifting their journal collections to electronic-only format and realigning their collection development policies to support this framework. In many cases, these libraries are including these policy changes in very public venues designed to justify their decisions and involve stakeholders, especially faculty and students. These changing collections and policies have broad-reaching implications from budgetary allocations to workflow processes, staffing, and relationships with user communities.

Hunter (2002) provides an excellent overview of the history of transitioning to electronic serials. She points out that, even though electronic-only subscription models were available from some major publishers since the mid-1990s, the majority of academic libraries did not begin to embrace this subscription model until 2000. Hunter found that libraries based their decisions to "go e-only" on several factors: an inability to support both print and electronic formats; attractive cost-savings for electronic-only subscriptions; and a need for realized savings with regard to shelf space and binding costs.3

Many authors have reported on the rising costs of serials and the impact on library budgets. Dingley (2005) reports that the average cost of serials increased by 731 percent, from \$54 in 1984 to \$449 in 2005.4 These increases have had a dramatic and all too familiar effect on libraries' materials budgets. In his analysis of ARL libraries' uptake of electronic resources from 1997 to 2004, Stoller (2006) finds that, on average, spending for e-resources by libraries has increased by 85 percent each year. 5 This represents a jump from \$50.5 million in 1997 to \$301.7 million in 2004 amongst a sample of the largest and smallest ARL academic libraries. 
Aside from budgetary implications, the uptake of electronic resources in academic libraries has been controversial for many reasons. Reservations of librarians regarding the transition to electronic-only collections have centered on concerns over potential negative feedback from users. Will there be a significant difference in quality of service if content is delivered via a networked server compared to traditional print access? What are the logistics of assimilating collections of libraries participating in consortial serials access arrangements? What may be the impact on users of a potential inability to commit continuing funds for electronic access and consequences of publishers discontinuing service? Could there be potential delays in publication time for content delivered online? How will universities handle higher demand on campus networking infrastructure to support online access? Will there be assurances that perpetual access rights can be met and that publishers will take appropriate archival measures (Hunter, 2002)?6 Cole (2005) highlights that consistent and perpetual access is an important issue in the everchanging marketplace of scholarly communication.7 Changes in journal titles, publishers, and pricing and packaging models require careful thought and planning for a shift to electronic collections and purchasing models. Libraries experimenting with providing access to serials via electronic-only serials collections have reconciled many of these concerns by negotiating consortial agreements for electronic access serials and working with publishers to secure perpetual-access rights. Users have for the most part demonstrated that they expect electronic access to serials, thereby influencing institutional decisions to build more robust networking infrastructures as well as decisions to commit more funds for electronic content. 
In contrast, for those libraries that are providing pay-per-view serials access, most of these concerns are irrelevant because they are focusing on access only, not on ownership or rights to content. Pay-per-view serials access is fundamentally different from electronic-only access in that pay-per-view access is not concerned with traditional archival or preservation roles. Nevertheless, as Montgomery points out (2003), moving toward an electronic-only serials collection or merely just access via pay-per-view involves giving up some control and taking on some risk: "Given the chaotic state of scholarly publishing, we do what is best for our current users within the limits of our budget. We understand that this electronic collection based upon publishers' packages is fragile since it is extremely sensitive to budget reductions."8

\section{Overview of the Case Libraries:}

The libraries discussed in this chapter have implemented two differing strategies for providing electronic access to serials: a wholesale shift to electronic-only journal collections and pay-per-view serials purchasing. The following institutions were selected for case studies based on their efforts to engage in evolving serials collections and purchasing activities and because they represent a cross-section of different types of academic institutions: University of Nevada - Las Vegas, Cornell University, University of North Carolina at Greensboro, and University of Wisconsin - Madison (see Table 4.1).9 Represented in this small sample are libraries that range from large land-grant institutions to younger liberal-arts institutions. Respondents from each institution were interviewed by phone and email during September 2006. The diversity and similarities in 
strategies and perspectives of the case libraries provide guidance for libraries that are considering following in their footsteps as well as enable reflection and evaluation of experiences with other libraries that have already been experimenting with pay-per-view serials access or have committed to electronic-only serials collections.

[Insert Table 4.1: Characteristics of case libraries based on Carnegie Classification, student population, total operating budget and total collections and acquisitions budget.]

All four universities are classified as large four-year doctoral degree-granting institutions under the Carnegie classification system. University of Wisconsin-Madison is the largest in terms of student population with 41,000 students reported for Fall 2006. University of North Carolina at Greensboro is the smallest university with 14,000 students reported for Fall 2006. Founded in 1957, the University of Nevada - Las Vegas (UNLV) is by far the youngest of the four case universities. Cornell University and University of Wisconsin-Madison are both members of the Association of Research Libraries (ARL) and rank in the top ten and top twenty, respectively. While Cornell University Libraries reported the greatest operating budget (\$50.2 million for 20042005), University of North Carolina at Greensboro and University of Nevada - Las Vegas report the largest percentage of the operating budget devoted to collections and acquisitions (approximately 40 percent).

\section{Case Studies for Shifting to Electronic-Only Serials Collections}




\section{\#1 University of Nevada at Las Vegas (UNLV) Libraries \\ Respondents: Xiaoyin Zhang (Head, Materials Ordering and Receiving) and Michaelyn Haslam (Librarian, Materials Ordering and Receiving)}

\section{Background}

Since 2000, UNLV Libraries has been incrementally converting print journal subscriptions to electronic-only subscriptions. The motivations for this ongoing shift to electronic-only serials are three-fold and mirror the motivations of other research libraries that are transitioning to electronic-only subscriptions. These motivations include:

1) User expectations: to meet increasing expectations of faculty and students that online access to journals and databases should be extensive and ubiquitous, especially as research becomes a remote practice and as distance-education programs continue to develop and mature.

2) User needs: to provide more complete instruction services and resources to satisfy learning and research needs of the user community.

3) Functional necessity: library staff at UNLV recognized that to more efficiently manage serials workflows and processing, they had to make a decision to collect print or electronic formats, not both.

User expectations and the need for more efficient and manageable systems coalesced to form a tipping point for shifting to an electronic-only serials collection.

Before the inception of the shift to electronic-only serials collection practices in 2000, UNLV Libraries had 6,200 print subscriptions and a handful of electronic resources. Since then, UNLV Libraries has converted between 200-500 print 
subscriptions each year to an electronic-only format and has added many new electronic serials. As of late 2006, the serials collection consists of 17,000 electronic subscriptions and only 2,000 print subscriptions. As UNLV Libraries has worked to convert the collection, policies have been adopted stipulating that any new subscriptions should be electronic-only, when possible.

What is it about UNLV Libraries that makes this shift to electronic-only serials successful? As most academic libraries will attest, user demand and expectation for electronic access to resources have played a major role in the acceptance of electroniconly serials collections. Since 2000, UNLV Libraries has expanded consortial relationships, bringing in 3,500 new subscriptions through shared licensing and negotiation practices (Zhang and Haslam, 2005).10 In addition to changes in collection policies favoring electronic-only journals, the materials budget for electronic resources has also been increased to support these new policies. As a result, workflows were reorganized and staff resources were reengineered to accommodate these new practices.

\section{Process and Criteria}

In accordance with the criteria that UNLV Libraries uses to build the electroniconly serials collection, electronic-only subscriptions are favored with few exceptions when both print and electronic formats are available. Print subscriptions are maintained for Special Collection acquisitions, when print is made mandatory with electronic format by publishers and/or vendors, and in cases where a password is required for electronic access. 


\section{Impacts on Budget and Long-term Planning}

Print journals and monographs are being cut to support growing e-resource needs and the tools to support them. At UNLV Libraries, the shift to electronic-only serials has meant that spending on print serials - subscription costs as well as nonsubcription costs (e.g., staffing, materials, binding, shelving, space) - has been cut back and will continue to be cut back. According to the respondents, while electronic subscriptions usually do not cost more than print-only subscriptions, the impact of inflation on "buying power" remains the same. Incentives such as buying in bulk via electronic journal packages have fueled the fire of electronic-only journal collection-building. Discounts for bundled packages and journal archives or backfiles are just as popular at UNLV Libraries as they are elsewhere. Because of these incentives, funds allocated for books at UNLV Libraries have been used more and more to support journal subscriptions; this trend, of course, is not unique to UNLV Libraries. Moreover, with a heavy focus on electronic journal collections, UNLV Libraries has had to add new budget lines to purchase tools for managing access such as e-journal finders, link resolvers, and metasearch products. The respondents also described a recognized need to increase staffing resources to better analyze use statistics and handle complex licensing.

One major concern with respect to long-term planning and the future of the collection for the respondents is that UNLV Libraries is leasing much of the journal content rather than owning the content. Backfile or journal archive content, while "owned," is hosted remotely, leaving the onus of archiving and access on the publisher or vendor and taking control away from libraries. 
The shift to electronic-only serials has also impacted long-term strategic planning at UNLV Libraries. In the Strategic Plan for 2005-2010

(www.library.unlv.edu/about/strategic_goals.pdf), UNLV Libraries has stipulated that increases in the base budget and any one-time end-of-year funds will be used to enhance the availability of resources, especially electronic resources. Any additional future funds will also be used to organize an evaluation of all remaining print subscriptions and explore the possibility of leveraging aggregator databases as alternative means of access to low-use print resources.

\section{Impacts on Staffing and Workflows}

UNLV Libraries’ transition from print to electronic resources has had major ramifications for job responsibilities and position descriptions as well as organizational structure. In the fall of 2000, the unit primarily responsible for print serials processing and management was reorganized so that members of that unit could assume the responsibility of processing and ongoing maintenance of all electronic resources. Workflows for selecting, acquiring, receiving, and claiming were reconfigured. All position descriptions were altered to reflect the organizational and functional changes to the unit. Serials receiving processes are now handled by a student assistant working twenty hours a week. Claims processes, which are relevant only for print journals, have been reduced. In addition, a new position, Electronic Resources Librarian, was created in 2003 to oversee the management and processing of electronic resources. Down the road, UNLV Libraries anticipates that processing of print serials will be established as a separate functional unit. 
Evaluation Tools and Benchmarking Methods

The UNLV Libraries respondents explained that it is too soon to gauge the economic impact and efficiency of workflows implemented as a result of the shift to an electronic-only serials collection. Too many changes and fast expansion to electroniconly collection practices have made it difficult to measure outcomes. Nevertheless, a combination of in-house and vendor-developed tools has been used to manage the transition and will continue to be used for the long-term. Commonly-used programs such as Microsoft Access and Excel as well as the integrated library system, Innovative Interfaces, Inc. have supported most of their needs.

\section{\#2 Cornell University Libraries}

Respondents: John Saylor (Director, Engineering Library and Collection Development for National Science Digital Library) and Bill Kara (Head, Technical Services, Mann

\section{Library)}

Background

According to the respondents, two years ago, Cornell University Libraries investigated potential subscription and non-subscription savings (e.g., staff, resources, space) of converting the serials collection to electronic-only format. The respondents explained that dramatic savings could be attained by eliminating duplicate subscriptions. Staff at Cornell University Libraries set forth a goal of canceling duplicate serials and converting existing subscriptions to electronic-only access for 4,000 journal titles over a 
three-year period. The titles spanned the sciences, social sciences, and humanities. In the life sciences, many duplicate subscriptions existed across different Cornell University libraries - these "low-hanging fruit" were the first to be cancelled. Thus far, the library system has incurred 1,500 subscription changes from print to electronic format with around one thousand more being converted to electronic-only for 2007. Much of the savings realized thus far have resulted from the elimination of duplicate print subscriptions amongst the life sciences. The transition of engineering, mathematics, and physical sciences journals that have already transitioned to electronic-only subscriptions has received strong, positive feedback from faculty and students in these disciplines. The latest push for the transition from print to electronic has moved beyond science libraries to focus more on humanities and social sciences journals.

\section{Process and Criteria}

Decision-making criteria for converting journals to electronic-only or maintaining print are described on the Cornell University Libraries website on scholarly communication (http://www.library.cornell.edu/scholarlycomm/serials/eonly). The criteria are based on function within the context of a particular institution (e.g., high profile journals, importance for browsing, image quality, aesthetic value), availability of electronic archives in accordance with publishers' policies for long-term preservation, commitment to preservation of journals at a local level, responsibility to retain print subscriptions at a local level (e.g., based on consortial agreements), time delays and reliability of publication based on publishers' practices, and quality/quantity of electronic versus print content based on publishers' practices. This is an excellent set of criteria for 
other academic libraries to consider in planning a conversion to an electronic-only serials collection. Some of these criteria are library-specific and some are publisher-specific. For example, considerations of the artifactual or aesthetic value of serials will certainly differ from one library collection to another while guaranteed archival access to serial content is dependent on publishers. Other criteria might include the presence or absence of complete holdings for serials and the ownership of online serials backfiles.

\section{Impacts on Budget and Long-term Planning}

In terms of budgetary savings, the respondents from Cornell University Libraries reported an initial savings of 10 percent by eliminating duplicate subscriptions and converting many existing subscriptions to electronic-only. In terms of long-term planning, the respondents indicated that the project is still in flux - too many aspects are still evolving in terms of statistics collecting, package plans, title changes, and ownership changes. In addition to the need for new systems and technical reporting functionality to support an electronic-only serials collection, administrators at Cornell University Libraries are considering journal use and necessity of physical presence of print journals as they plan for the future. Job descriptions are also changing and new positions are being considered for the future.

\section{Impacts on Staffing and Workflows}

The respondents indicate that there is anecdotal evidence that reallocation of staff time and responsibilities have had a positive impact. Even so, vacant positions have been 
realigned or recouped in different ways, and many staff responsibilities have changed regarding record maintenance and purchase order workflows.

By undergoing the process of reviewing titles for conversion to electronic-only format, librarians and staff were able to get a better handle on serials records and payments and developed better solutions for managing subscriptions. This experience was also an opportunity to bring more librarians up to speed on evaluating statistics on use of the collection.

\section{Evaluation Tools and Benchmarking Methods}

The type of information collected to evaluate the effectiveness of converting the collection to electronic-only format included subscription savings for duplicates, subscription savings for electronic-only acquisitions, number of issues no longer received, number of journals no longer needing to be bound, and the number of check-ins pre- and post-transition to an electronic-only serials collection. Librarians involved in the conversion process are also estimating the time required to review the physical quality of journals, review licenses, and update licenses for different kinds of publishers to better understand how to approach these processes more efficiently. Some publishers have hundreds of titles, so they can all be dealt with easily, while others have only a few titles. Different scales have dramatic implications for time spent on decision-making. 


\section{Case Studies for Pay-Per-View Serials Access}

\section{\#3 University of North Carolina at Greensboro (UNCG) Libraries \\ Respondent: Beth Bernhardt (Electronic Journals/Document Delivery Librarian and Head of ILL)}

Background

Several major changes across academic programs at the University of North Carolina at Greensboro brought about a project at UNCG Libraries to provide access to serials via a pay-per-view model. In 2001, a distance-education program was established with its own source of funding. Since that time, UNCG Libraries has provided access for the distance-education students and faculty. For the most part, interlibrary loan is insufficient for these users, who expect quick and efficient access to resources. In addition, UNCG Libraries has moved from a focus on music education to expanding its programs to include a new science center specializing in biotechnology and genetics. As a result, UNCG Libraries has had to determine how to provide access to subject-specific journals that best serve these new programs.

At the same time that these developments were taking place, EBSCO and FirstSearch began offering article pay-per-view access services. UNCG Libraries decided to try both services, effectively adding many new journal titles to the collection. Over the past few years, they have been working with Blackwell, Kluwer, Ingenta, Elsevier, Wiley, Ovid, and the American Institute of Physics to provide pay-per-view 
serials access (Bernhardt, 2003). 11 Overall, UNCG Libraries has added 3,000-3,500 journals via pay-per-view serials access.

\section{Process and Criteria}

Journals included in the pay-per-view serials access model are those journals that are not already owned by UNCG Libraries, have a surcharge for online access, or have an imposed embargo period. In some cases, access to newly requested journals is provided on a provisional basis via pay-per-view access to determine actual use before committing continuing funds to the new journals.

After one year of experimenting with pay-per-view serials access, the Libraries recommended that twenty-one titles be added to the collection because it was more costeffective to subscribe to the journals than to continue to provide access via a pay-perview mechanism. Most of these subscriptions were for psychology journals as well as social science journals. The science journals still proved too cost-prohibitive to subscribe to, so the Libraries retained pay-per-view access for these titles.

\section{Impacts on Budget and Long-term Planning}

At the project's inception, UNCG Libraries received funding for the pay-per-view serials access project from the distance-education program. Using pay-per-view serials access as an alternative to subscriptions, UNCG Libraries paid an average of \$400-500 per year per journal. 
As evaluation and long-term planning continue, UNCG Libraries is trying to find the best way to provide access to students and faculty. Because some recently established consortial partnerships provide much more cost-effective journal access, some of the pay-per-view serials access models are being phased out. Currently, UNCG Libraries continues to receive funds from the distance-education program to support payper-view access for many science journals.

\section{Impacts on Staffing and Workflows}

The respondent described the overall impact of the pay-per-view serials access approach as minimal in terms of hiring more staff. Much of the additional work for the pay-per-view project was appended to an existing position responsible for serials management, with some of the responsibilities for collecting statistics being shared with another staff position. With regard to access and copyright issues decisions, no additional work procedures were necessary. Because patrons can purchase and download articles on their own via the pay-per-view serials access model, the responsibility of UNCG Libraries to follow proper copyright restrictions is removed. Users are made aware of copyright issues when they download the articles directly from the publishers.

\section{Evaluation Tools and Benchmarking Methods}

As part of their evaluation process, staff members at UNCG Libraries have tracked statistics including dates of access, dates of publications accessed, titles of articles, number of articles purchased, cost of each article, and the status of the journals 
accessed if owned in print. Most of this data is provided by the publisher or vendor along with invoices or regular reports.

To enable users to discover the content provided via pay-per-view serials access, UNCG Libraries added these journal titles to its Journal Finder tool. Each user must log into the network and authenticate in order to access these journals. Under this set-up, UNCG Libraries can also track usage and requests deriving from both on-campus and off-campus users.

\#4 University of Wisconsin at Madison (UW) Libraries

Respondents: Deborah Helman (Director, Wendt Library), Richard Reeb (Associate

Director, Collection Development and Technical Services), and Jean Gilbertson (Director, Steenbock Library)

\section{Background}

Over the past several years, the University of Wisconsin-Madison Libraries has been trying to control the amount of acquisitions and collections money given to a few large publishers. Initially this was accomplished by reducing the number of duplicate print subscriptions and by canceling unique high-cost, low-use subscriptions. With the support of the Director of Libraries and campus administration, librarians eventually wanted to determine if they could greatly improve user access to canceled journals by buying articles directly from publishers rather than relying on interlibrary loan channels. The assumption was that purchasing articles would cost significantly less than the 
subscription price. The pilot project was initiated in January 2005 and, while evaluation of the project is ongoing, University of Wisconsin-Madison Libraries has reached the point where pay-per-view is proving to be a cost-effective and user-friendly alternative for many high-cost journal subscriptions with relatively low demand.

\section{Process and Criteria}

The journals that have been included in the project were cancelled over a period of several years. Therefore, the criteria used to select the journals carried over from prior serials cancellations: subscription cost, inflation rate, usage levels, relevance of subject content, faculty/researcher feedback, and alternate routes for providing access. The project currently includes 700 previously cancelled journal titles. Preliminary data showed that about 60 percent of the cancelled journals generated five or less article requests in the first year. There were 5,300 articles purchased for users via pay-per-view in the last fiscal year. .

After the first year of the project, a few titles were identified for which subscriptions should be reinstated because article demand exceeded or met subscription cost. The respondents noted that, since social science journals tend to be less expensive than science journals, using pay-pre-view for social science journals could more quickly reach the cost of a subscription.

\section{Impacts on Budget and Long-term Planning}

Funds for the project did not come from the collection budget, but came from funds secured by the Director of Libraries. One respondent made an important 
distinction in the approach to the project: “This project is being supported through special funding from campus for journal 'access' rather than journal 'acquisitions.'” Partly through the bulk purchase of article "tokens" and also through negotiating a license agreement, UW Libraries has been able to reduce the per-article cost significantly.

\section{Impacts on Staffing and Workflows}

UW Libraries has not explored the pay-per-view serials access model enough to determine its potential impact on long-term collection development policies. However, it is clear that the pay-per-view option will impact decisions about serials renewals. Recent years' budgets have been restrictive such that UW Libraries is continually forced to rethink collection development strategies. This project has been part of this continuum of assessment, evaluation, and response to increased journal costs and inadequate budgets. Librarians at UW Libraries have used this as an opportunity to spend money differently and focus spending on certain core collections.

All of the pay-per-view rapid article delivery processing is conducted by the campus interlibrary loan staff. As a result of the project, ILL staff members have changed their workflows significantly. In the more streamlined process, each staff member follows each request through to delivery, decreasing transaction times by ordering articles directly from publishers and simplifying the number of steps necessary compared to a typical ILL transaction.

\section{Evaluation Tools and Benchmarking Methods}


A feedback and marketing mechanism for the project was established by including an email to each article requestor that indicated that their article access was part of a project to improve access to journals no longer available on campus (while not revealing all journal titles that were included in the project). The respondents indicate that UW Libraries is still evaluating if the "increased direct costs (for article buying rather than using ILL) and the indirect staffing costs (which are harder to measure) are justified by what has turned out to be an overwhelmingly positive response by users.”

\section{Summary and Lessons Learned}

The case studies presented in this chapter offer differing perspectives for a nearly wholesale shift to an electronic-only journal collection and an emerging method of access via a pay-per-view serials purchasing model. Librarians from a cross-section of different types of academic institutions were interviewed regarding their experiences and perspectives with evolving purchasing and collection models for serials.

University of Nevada-Las Vegas Libraries and Cornell University Libraries were interviewed regarding their experiences transitioning to a nearly wholesale electroniconly serials collection. Their lessons learned vary across issues of staffing, technical infrastructure, and budget. For both institutions, ensuring that all staff are equally well informed and have a common understanding of goals and issues related to the transition to electronic-only serials has been a challenge. In terms of staffing, UNLV Libraries found that more staff time has been necessary to maintain and resolve access-related issues than was initially expected. Hesitations amongst staff and users at both 
institutions have had to be overcome. At Cornell University Libraries, some selectors have been more cautious about this transition while others have embraced the move to electronic-only access. In the humanities, the option to go electronic-only has been challenged by faculty due to concerns about archival access and the preservation policies of publishers. Many of the subsequent conversations between faculty and library staff have revolved around scholarly communication issues and have resulted in an opportunity to educate both librarians and faculty about these issues.

Overall, the experiences at both institutions have brought about a common awareness of collection issues amongst librarians, faculty, and students. The respondents at Cornell Libraries explained that the experience has been unifying for selectors because it has given them the opportunity to work together on a common project. The UNLV Libraries' respondents underscore the importance of establishing an internal system of open and clear communication as well as support for staff that are expected to adapt to changes in workflows. Alongside a solid infrastructure for communication and support, they highlight a critical need for a good tracking mechanism for all electronic journals to enable uninterrupted service.

The non-subscription savings at Cornell Libraries have had a very important impact on the system; they have been able to clean up records, check on payments, identify ways to better manage subscriptions, and engage more selectors in taking an active role in evaluating use statistics. They have also given feedback to publishers and enabled them provide better services. One of the overall lessons learned was that there were many instances where collections and purchasing functions need more centralized 
procedures for gathering, researching, and reviewing statistics about use and value of the collection as a whole.

The respondents at UNLV Libraries also point out that users have been very happy with the efforts of UNLV Libraries to make as many journals as possible available electronically. The respondents comment that, "Usually the electronic use is so much higher than for the print equivalent, it feels like we are providing a much needed service to our library community. It is worth working through rough spots in order to provide access to resources that get used so much.”

Librarians at the University of North Carolina at Greensboro Libraries and University of Wisconsin-Madison Libraries were interviewed regarding their experience with a pay-per-view model of serials access. Overall, for both institutions, it is evident that pay-per-view serials access is different for each library in terms of subject areas that are targeted for pay-per-view access and impacts on workflows and staffing.

Reactions from administration at both institutions have been very supportive of these experimental methods devoted to saving money and time. Feedback from users has been positive with few exceptions. At UNCG Libraries, some users complained that some of the publishers' interfaces are not intuitive with regard to ordering articles via the pay-per-view system. Feedback at UW Libraries has also been positive with a turnaround time averaging between a few hours to less than half a day. While enduring the pressure of journal cancellations, faculty and researchers are encouraged when offered the rapid article delivery access. In particular, users requesting articles under grant-proposal and manuscript deadlines "greatly appreciated” the rapid article delivery access. The UW respondents added that "many users commented on how the rapid 
delivery improved their productivity as researchers (being able to move projects ahead more quickly)." Some users made suggestions about how to spend library funds or expressed concern about spending money on such a granular scale. Issues of subscription cost for a journal versus cost per article opened opportunities for educating and communicating with faculty about the costs of scholarly communication. In addition, the quality of images, especially in the sciences, is often decreased after going through the standard photocopying and scanning process of ILL. Because the articles come directly from the publisher, pay-per-view serials access has been a great benefit for researchers needing high-quality images. The respondent at UNCG Libraries added that libraries should rethink a pay-per-view serials access strategy if the collections and acquisitions budget becomes over-used. Every library should already have a core set of journals in their collection; pay-per-view articles should only meet the needs for journals at the outskirts of the core collection.

For UNCG Libraries, taking advantage of consortial leveraging for subscription costs has eliminated one of the major disadvantages of pay-per-view serials access: the lack of archival access rights. Since UNCG Libraries has been participating in the Carolina Consortium, much of the pay-per-view serials access has decreased (approximately 80 percent). With regard to their consortial relationships in which access to serials is dependent on all partner libraries participating in a publisher license, both institutions are considering the impacts on their partner libraries in choosing to engage in pay-per-view serials access in terms of not having as many journals to share with consortium partners. 
Regarding publishers' reactions, the respondent at UNCG Libraries reported that some publishers are leery to get involved with pay-per-view serials access because of concerns that it might have a negative impact on their subscription revenues.

Additionally, some publishers were new to the idea of pay-per-view serials access and had to set-up new processes for accounting and authentication/recognition in order to accommodate the needs of UNCG Libraries. Both institutions have discovered that there is a high level of record-keeping necessary to document and evaluate a project like this, including tracking articles being purchased, journal titles, subscription costs, and costs of articles among other details.

Wholesale conversion to electronic-only serials collections and pay-per-view serials models do have interesting implications for library collections and acquisitions functions as well as future collection development strategies. By experimenting with evolving collections and purchasing models, the four case libraries have developed core serials collections and have looked more closely at how and why libraries subscribe to titles and how selection decisions impact future decisions regarding collection focus, preservation and access. With regard to impacts on collection focus, consortial arrangements with publishers for electronic-only collections may be an attractive option but it comes with its own drawback, namely loss of specialized collections. Eells (2004) warns against the homogenization of library collections and suggests that "as decisions are made on how to configure collections, and on how to distribute limited library funding, librarians must maintain a strong connection to their users and an awareness of their preferences and needs.”12 
Opportunities to connect with users and develop an awareness of their expectations have arisen out of the experiences of the case libraries. As demonstrated by Cornell University Libraries’ experience, concerns and misunderstanding about the overall impact of evolving purchasing and collection models on the economics of scholarly communication can be addressed with librarians, faculty and administrators.

Neither model is a perfect option for most libraries. Customization of processes, uncovering roadblocks, dealing with resistance to change internally and externally, and confronting concerns about an uncertain future will vary across different library contexts. However, both models offer opportunities to meet the increased demand of e-resources by patrons and develop tools and strategies to manage electronic collections.

\section{Notes}

1. Donald W. King and Carol Tenopir, "An evidence-based assessment of the ‘author pays’ model,” Nature Forum (2004): http://www.nature.com/nature/focus/accessdebate/26.html (accessed January 12, 2007).

2. Peter Boyce, Donald W. King, Carol Montgomery, and Carol Tenopir, "How electronic journals are changing patterns of use,” Serials Librarian 46 (2004): $121-141$. 
3. Karen Hunter, “Going 'Electronic-Only': Early Experiences and Issues,” Journal of Library Administration 35 (2002): 51-65.

4. Brenda Dingley, "U.S. periodical prices - 2005," http://www.ala.org/ala/alctscontent/alctspubsbucket/alctsresources/general/periodi calsindex/05USPPI.pdf (accessed January 12, 2007).

5. Michael Stoller, "A decade of ARL collection development: a look at the data," Collection Building 25 (2006): 45-51.

6. Hunter, “Going ‘Electronic-Only’,” 61-63.

7. Louise Cole, “A journey into e-resource administration hell,” Serials Librarian 49 (2005): 141-154.

8. Carol Hansen Montgomery, "The evolving electronic journals collection at Drexel University,” Science and Technology Libraries 24 (2003): 184.

9. Xiaoyin Zhang and Michaelyn Haslam, email exchange with author, September 21, 2006; John Saylor and Bill Kara, telephone interview with author, September 8, 2006; Beth Bernhardt, telephone interview with author, September 1, 2006; Deborah Helman, Richard Reeb and Jean Gilberston, telephone interview with author, September 18, 2006.

10. Xiaoyin Zhang and Michaelyn Haslam, "Movement toward a predominantly electronic journal collection,” Library Hi Tech 23 (2005): 82-89.

11. Beth Bernhardt, "Pay per view: a library’s perspective,” Presented at the North Carolina Serials Conference, Chapel Hill, NC, April 2-4, 2003.

12. Linda L. Eells, 2004. "For better or for worse: the joys and woes of e-journals," Science and Technology Libraries 25 (2004): 46. 
